1 School of Psychology, Swansea University

2 School of Psychology, University of Sussex

3 University College London

4 Loughborough University

Cite this as: BMJ 2021;375:n3028 http://dx.doi.org/10.1136/bmj.n3028

Published: 06 December 2021

\title{
Covid-19: What we have learnt from behavioural science during the pandemic so far that can help prepare us for the future
}

\author{
The emergence of the omicron variant has raised concerns that the pandemic is not yet over. These \\ authors outline four key lessons that governments need to learn from to protect against future \\ pandemics
}

\section{Simon Williams, ${ }^{1}$ John Drury, ${ }^{2}$ Susan Michie, ${ }^{3}$ Elizabeth Stokoe ${ }^{4}$}

The covid-19 pandemic is far from over. Over the autumn, the UK has seen between 30 and 50 ooo daily cases. Globally, cases have begun to rise again recently after months of steady decline. Additionally, the recent emergence of the Omicron (B.1.1.529) variant has caused concerns due to the possibility of it having a larger degree of immune escape due to the high number of mutations on its spike protein. ${ }^{1}$ Now is a good time to think about what we have learnt from behavioural science during the pandemic so far, and how it will help in the future. Doing so cannot only help to minimise the harms of the current pandemic, and plan for future outbreaks, but can also inform our thinking about wider issues, from vaccine uptake to public health messaging. Here we outline four key lessons.

Firstly, research during the pandemic has taught us that trust is one of public health's biggest prophylactics. Evidence suggests that trust in government is one of the biggest predictors of adherence to public and social measures and vaccine acceptance..$^{2-4}$

One way in which trust is harmed is if the reasons or "the science" behind decision making processes are not sufficiently transparent, as this is unlikely to instil trust in authorities. In the UK, questions have been raised over the transparency and timeliness of certain policy decisions, for example, the costly delays of the first lockdown and in offering vaccinations to 12-15 year olds. ${ }^{6}$ Another way in which trust is harmed is if people sense there being "one rule for them, another for us." Those in positions of authority need to be seen to be following the rules they expect the public to follow-something that has at times been lacking in the UK. Finally, trust is also harmed if people feel like they are not being trusted to do enough or act appropriately when needed. Trust is therefore a two-way street. In the UK for example, some government policy and messages have implied that the public cannot be trusted to maintain motivation to stick to "lockdown" rules or to use self-isolation support responsibly. ${ }^{7}$

Although rates of covid-19 are currently high in Denmark, it serves as a good example of how trust in government, and of its people, can provide a solid basis for an effective pandemic response, and how this can contribute to high levels of adherence and support for covid-19 policies and vaccine acceptance. ${ }^{89}$

This is partly due to Denmark being historically a high trust country, which in turn is partly a product of a long standing commitment to reducing inequalities and providing strong welfare protections, but also partly due to the decisive implementation of strong pandemic protections. ${ }^{8}$ Building people's trust in government, and building a government that trusts its people, is a long term investment for the next pandemic.

Secondly, research shows that people's adherence to covid-19 measures has been generally high throughout the pandemic. ${ }^{10}$ However, behavioural science has also reminded us that behaviours are not simply the result of individual motivation - they are as much a product of our opportunities and capabilities to adhere to measures, such as self-isolation. ${ }^{11} 12$ Those most economically and socially vulnerable-for example, those in deprived neighbourhoods and in certain Black and ethnic minorities communities-have been the most impacted by the pandemic. Improving their opportunities and capabilities to engage in protective behaviours is something that governments should start to heavily invest in now. Preparing for the next pandemic should mean seeking to reduce inequalities in opportunities and capabilities-something that requires fundamental political, economic, and social investment and development.

Thirdly, clarity and consistency-of policy and message-is also key. Adherence is not simply a matter of motivation, but also of people's (cap)ability to understand rules, which in turn relies on rules to be clearly formulated and communicated. In the UK, in particular, the lack of consistency between policies and advice across place and time has led to confusion or "mixed messages," which in turn can jeopardise adherence. ${ }^{13}$ For example, in England, the lack of a consistent message and policy across the UK on facemasks has likely contributed to the reduction of this behaviour we have seen before masks were re-mandated on 30 November 2021 on public transport and in shops. ${ }^{14}$ This lack of clarity may have created doubt for some in the value of this behaviour, which may be an unwanted legacy for the next covid-19 wave or pandemic in the UK, in contrast to other countries that have taken a stronger and clearer stance on masks.

Fourthly, pandemic preparedness should be focused on protection over restriction. Protecting against future pandemics requires much more than providing enough facemasks, hand sanitizer, and personal protective equipment. It requires us to rethink how we work-for example, how governments support 
employers to support their employees to work from home when possible (something that will reduce future cases and deaths from flu and other respiratory illnesses as well as from covid-19).

Although current covid-19 rates in the UK are extremely high, rates of home working are not particularly high and we know that those who go into a workplace have significantly more contacts than those who work from home. ${ }^{14}$ The UK did not put sufficient support in place for employers to maximise home working, or sufficient financial or practical self-isolation support measures, or improvements in statutory sick pay. The benefits from investing in a healthier and fairer society have been brought into sharp relief by covid-19, and these extend beyond pandemic management.

Competing interests: SM and JD participate in the Scientific Pandemic Influenza Group on Behavioural Science (SPI-B) and are members of Independent SAGE. ES participates in the Policing and Security subgroup of SPI-B (SAGE) and is a member of the Behavioural Advisory Group of Independent SAGE.

Provenance and peer review: not commissioned, not peer reviewed

1 Dyer 0. Covid-19: South Africa's surge in cases deepens alarm over omicron variant. BMJ 2021;375:n3013. doi: 10.1136/bmj.n3013. pmid: 34862184

2 Wright L, Steptoe A, Fancourt D. Predictors of self-reported adherence to COVID-19 guidelines. A longitudinal observational study of 51,600 UK adults. Lancet Reg Health Eur 2021;4:100061. doi: 10.1016/j.lanepe.2021.100061. pmid: 33997831

3 Williams SN, Armitage C), Tampe T, Dienes KA. Public perceptions of non-adherence to pandemic protection measures by self and others: A study of COVID-19 in the United Kingdom. PLoS One 2021;16:e0258781. doi: 10.1371/journal.pone.0258781. pmid: 34710125

4 Burgess RA, Osborne RH, Yongabi KA, etal. The COVID-19 vaccines rush: participatory community engagement matters more than ever. Lancet 2021;397:8-10. doi: 10.1016/S0140-6736(20)32642-8. pmid: 33308484

5 UK's coronavirus policy places too much responsibility in the hands of the public. BMJ Opinion. March 2020. https://blogs.bmj.com/bmj/2020/03/17/uks-coronavirus-policy-places-too-muchresponsibility-in-the-hands-of-the-public/

6 Mahase E. Covid-19: Vaccine advisory committee must be more transparent about decisions, say researchers. BMJ 2021;375:n2452. doi: 10.1136/bmj.n2452. pmid: 34620583

7 Reicher S, Drury J. Pandemic fatigue? How adherence to covid-19 regulations has been misrepresented and why it matters. BMJ2021;372:n137. doi: 10.1136/bmj.n137. pmid: 33461963

8 Nielsen JH, Lindvall J. Trust in government in Sweden and Denmark during the COVID-19 epidemic. West Eur Polit 2021:44:5-6, 1180-204. doi: 10.1080/01402382.2021.1909964.

9 Lindholt MF, Jørgensen F, Bor A, Petersen MB. Public acceptance of COVID-19 vaccines: cross-national evidence on levels and individual-level predictors using observational data. BMJ Open 2021;11:e048172. doi: 10.1136/bmjopen-2020-048172. pmid: 34130963

10 Wright L, Fancourt D. Do predictors of adherence to pandemic guidelines change over time? A panel study of 22,000 UK adults during the COVID-19 pandemic. Prev Med 2021;153:106713. doi: 10.1016/j.ypmed.2021.106713. pmid: 34242662

11 Bavel JJV, Baicker K, Boggio PS, etal. Using social and behavioural science to support COVID-19 pandemic response. Nat Hum Behav 2020;4:460-71. doi: 10.1038/s41562-020-0884-z. pmid: 32355299

12 Michie S, West R. Sustained behavior change is key to preventing and tackling future pandemics. Nat Med 2021;27:749-52. doi: 10.1038/s41591-021-01345-2. pmid: 33972794

13 The public aren't complacent, they're confused-how the UK government created "alert fatigue." BMJ Opinion. February 2021. https://blogs.bmj.com/bmj/2021/02/19/the-public-arent-complacentthey-are-confused-how-the-uk-government-has-created-alert-fatigue/

14 CoMix study. Social contact survey in the UK https://cmmid.github.io/topics/covid19/comix-reports.html 